\title{
Endometriosis in Monozygotic and Dizygotic Twins: A Review of Literature
}

\author{
Raimondo $D^{1 *}$, Mastronardi $\mathbf{M}^{1}$, Mabrouk $\mathbf{M}^{2}$, Arena $\mathrm{A}^{1}$ and Seracchioli $\mathbf{R}^{1}$ \\ ${ }^{1}$ Department of Obstetrics, Gynecology and Human Reproduction Physiopathology, Dipartimento di Scienze Mediche e Chirurgiche (DIMEC), S. Orsola Hospital, University \\ of Bologna, Massarenti, Bologna, Italy \\ ${ }^{2}$ Faculty of Medicine, Department of Obstetrics and Gynecology, University of Alexandria, Egypt

\begin{abstract}
Endometriosis is a common estrogen-dependent inflammatory disease and a major contributor to pelvic pain and subfertility in women of reproductive age. Its etiology and pathogenesis are not well known yet, but different studies had highlighted its multifactorial nature, influenced by both genetic and environmental components. This minireview analyzes the prevalence of the disease and the concordance for the presence and stage of endometriosis in monozygotic (MZ) and dizygotic (DZ) twins. A higher concordance for the presence of the disease in $M Z$ twins rather than DZ twins was observed, with a statistically significant difference ( $p$-value $<0.05)$. Only one study had evaluated the concordance for endometriosis stage within $\mathrm{MZ}$ twins, observing a high rate of concordance. Genetic component seems to play a pivotal role in the development of endometriosis and its severity.
\end{abstract}

Keywords: Endometriosis; Twins

\section{Introduction}

Endometriosis is one of the most common benign gynecologic diseases and is characterized by the presence of ectopic endometrial tissue outside the uterus. It is an estrogen-dependent inflammatory disease and a major contributor to pelvic pain and subfertility in women of reproductive age [1]. Although its etiology and pathogenesis are largely unknown, evidence shows that it is a complex multifactorial disease, where both genetic and environmental components contributing to susceptibility [2]. Studies on heritability have demonstrated familial accumulation, increased concordance in monozygotic (MZ) twins, and a 3 to 15 times higher risk in first-degree relatives of women with endometriosis compared with those in the general population [2,3-8].

The aim of the present study was to achieve a comprehensive review of pertinent and recent literature published in order to analyze the prevalence of the disease and the concordance for the presence and stage of endometriosis in $\mathrm{MZ}$ and $\mathrm{DZ}$ twins.

\section{Literature Review}

The following key words were used to conduct a computerized search of PubMed/Medline: "endometriosis" AND "twins" OR "hereditability" OR "familial endometriosis". Relevant full-text articles written in English from January 1994 to November 2018 containing a table of references were retrieved. Articles with less than 5 cases were not considered for the study. All references were searched to identify other pertinent articles. Number of twin pairs, number of twin pairs affected by endometriosis, concordance and discordance for the presence of endometriosis, concordance for stage of the disease were evaluated in general and distinguishing between $\mathrm{MZ}$ and $\mathrm{DZ}$ twins. Comparison of concordance for the presence of the disease between $\mathrm{MZ}$ and $\mathrm{DZ}$ twin pair were performed using a Chi-squared test. Statistical significance was set to the conventional $p$-value $\leq 0.05$.

\section{Results}

After a comprehensive review of the literature, 5 studies met our inclusion criteria. Data obtained from the revision of the Literature are summarized in Tables 1 and 2 .

Three studies selected twin pairs affected by endometriosis from a National Twin Registry $(2 ; 5 ; 19)$. Analyzing the data from these latter, the prevalence of endometriosis in twins was 8.6\% (825 twin pairs affected by endometriosis out of 9543 twin pairs in total). More specifically, the prevalence was $8.6 \%$ in MZ (437 twin pairs affected by endometriosis out of 5072 in total) and $8.6 \%$ in $\mathrm{DZ}$ (388 twin pairs affected by endometriosis out of 4471 in total) (Table 1).

\begin{tabular}{|c|c|c|c|c|c|c|}
\hline \multirow[t]{2}{*}{ Authors } & \multicolumn{2}{|c|}{$\begin{array}{c}\text { Number of twin } \\
\text { pairs }\end{array}$} & \multicolumn{2}{|c|}{$\begin{array}{c}\text { Number of twin } \\
\text { pairs with at least } \\
\text { one sister E+ }\end{array}$} & \multicolumn{2}{|c|}{$\begin{array}{c}\text { Prevalence of } \\
\text { endometriosis (\%) }\end{array}$} \\
\hline & MZ & DZ & MZ & DZ & MZ & DZ \\
\hline Moen et al. [18] & 8 & 0 & 8 & 0 & NA & NA \\
\hline $\begin{array}{l}\text { Hadfield et } \\
\text { al. [6] }\end{array}$ & 16 & 1 & 16 & 1 & NA & NA \\
\hline 'Treolar et al. [2] & 854 & 493 & 105 & 51 & $12.3 \%$ & $10.3 \%$ \\
\hline $\begin{array}{l}\text { Zondervan et } \\
\text { al. [19] }\end{array}$ & 623 & 377 & 73 & 39 & $11.7 \%$ & $10.3 \%$ \\
\hline Saha et al. [5] & 3595 & 3601 & 259 & 298 & $7.2 \%$ & $8.3 \%$ \\
\hline \multirow[t]{2}{*}{ Total $^{\mathrm{a}}$} & \multicolumn{2}{|c|}{9568} & \multicolumn{2}{|c|}{850} & \multicolumn{2}{|c|}{ NA } \\
\hline & 5096 & 4472 & 461 & 389 & NA & NA \\
\hline \multirow[t]{2}{*}{ Total $^{b}$} & \multicolumn{2}{|c|}{9543} & \multicolumn{2}{|c|}{825} & \multicolumn{2}{|c|}{$8.6 \%$} \\
\hline & 5072 & 4471 & 437 & 388 & $8.6 \%$ & $8.6 \%$ \\
\hline \multicolumn{7}{|c|}{$\begin{array}{l}\text { *Studies used to evaluate the total preval } \\
\text { E+: Patient affected by endometriosis } \\
\text { MZ: Monozygotic twin pairs } \\
\text { DZ: Dizygotic twin pairs } \\
\text { NA: Not applicable } \\
\text { aTotal considering all the studies } \\
\text { bTotal considering only the studies with }\end{array}$} \\
\hline
\end{tabular}

Table 1: Prevalence of endometriosis in twin pairs.

${ }^{*}$ Corresponding author: Dr. Diego Raimondo, Department of Obstetrics, Gynecology and Human Reproduction Physiopathology, DIMEC, S. Orsola Hospital, University of Bologna Massarenti, 13 - 40138 Bologna, Italy, Tel: + 39051 2144389; Fax: +39 051 2144392; E-mail: die.raimondo@gmail.com

Received December 18, 2018; Accepted December 27, 2018; Published December 31, 2018

Citation: Raimondo D, Mastronardi M, Mabrouk M, Arena A, Seracchioli R (2018) Endometriosis in Monozygotic and Dizygotic Twins: A Review of Literature. J Mol Genet Med 12: 383 doi:10.4172/1747-0862.1000383

Copyright: @2018 Raimondo D, et al. This is an open-access article distributed under the terms of the Creative Commons Attribution License, which permits unrestricted use, distribution, and reproduction in any medium, provided the original author and source are credited 


\begin{tabular}{|c|c|c|c|c|}
\hline Authors & \multicolumn{2}{|c|}{$\begin{array}{c}\text { Concordance for } \\
\text { Endometriosis (E+E+); } \mathbf{n}(\%)\end{array}$} & $\begin{array}{c}\text { Discordance for } \\
\text { Endometriosis (E+E-); } \mathbf{n}(\%)\end{array}$ \\
\hline & $\mathbf{M Z}$ & $\mathbf{D Z}$ & $\mathbf{M Z}$ & $\mathbf{D Z}$ \\
\hline $\begin{array}{c}\text { Moen et al. } \\
\text { [18] }\end{array}$ & $6(75 \%)$ & 0 & $2(25 \%)$ & 0 \\
\hline $\begin{array}{c}\text { Hadfield et } \\
\text { al. [6] }\end{array}$ & $14(87.5 \%)$ & $1(100 \%)$ & $2(12.5 \%)$ & $0(0 \%)$ \\
\hline $\begin{array}{c}\text { Treolar et } \\
\text { al. [2] }\end{array}$ & $18(17.1 \%)$ & $3(5.9 \%)$ & $87(82.9 \%)$ & $49(94.1 \%)$ \\
\hline $\begin{array}{c}\text { Zondervan et } \\
\text { al. [19] }\end{array}$ & $13(17.8 \%)$ & $2(5.1 \%)$ & $60(82.2 \%)$ & $37(94.9 \%)$ \\
\hline Saha et al. [5] & $30(11.6 \%)$ & $15(5 \%)$ & $229(88.4 \%)$ & $283(95 \%)$ \\
\hline \multirow{2}{|c|}{$102(12 \%)$} & \multicolumn{2}{|c|}{$749(88 \%)$} \\
\cline { 2 - 5 } Total & $81(17.6 \%)$ & $21(5.4 \%)$ & $380(82.4 \%)$ & $369(94.6 \%)$ \\
\hline
\end{tabular}

MZ: Monozygotic twin pairs

DZ: Dizygotic twin pairs

E+: Patient affected by endometriosis

E-: Patient without endometriosis

Table 2: Concordance and discordance for endometriosis in twin pairs.

The concordance for the presence of endometriosis between MZ and DZ twins was analyzed considering all the 5 studies. In MZ twins the concordance was $17.6 \%$ (81 twin pairs of 461 ), while in DZ twins it was $5.4 \%$ (21 twin pairs on 389), with a statistically significant difference ( $p$-value < 0.05) (Table 2). Regarding concordance for endometriosis stage, only Hadfield et al. had investigated a possible concordance within MZ twins, observing a high rate of concordance. Out of $14 \mathrm{MZ}$ twins with concordance for the presence of disease, 9 (64.3\%) were concordant for stage III-IV [6].

\section{Discussion}

The true prevalence of endometriosis in the general population is unknown, mainly because diagnosis is often overlooked by primary care doctors leading to an average delay of 10 years [9-12]. In literature, the estimated prevalence of endometriosis in women of reproductive age is between $2 \%$ and $10 \%$, reaching $50 \%$ among infertile patients $[2,5,13]$. In accordance with these data, the prevalence among twins was $8.6 \%$.

A higher concordance for disease in MZ twins rather than DZ twins was observed, with a statistically significant difference. In agreement with this finding, Somigliana et al. had documented an association between endometriosis and pigmentary traits [14]. They had observed a two-fold increase in the risk of disease in women with green/blue eyes and in those who had frequently/always skin burn reaction to first sun exposure. Considering pigmentary traits as heritable traits in humans, these findings suggest a shared genetic background between women with endometriosis $[14,15]$. We observed a different percentage of endometriosis concordance through the different studies. This discrepancy could be explained considering the selection bias (type of population included in the study: case series or patients from a National Twin Registry) and the several diagnostic methods adopted to detect endometriosis (questionnaires, medical records analysis, histological confirmation). Furthermore, many women affected by endometriosis are asymptomatic and in many symptomatic ones the disease is not diagnosed.

Only one study evaluated the concordance for endometriosis stage within MZ twins, observing a high rate of concordance. Therefore, genetic component seems to play a pivotal role in the development of endometriosis and its severity. Although the environmental effect (i.e., urban setting, diet) is suspected to be responsible for development of the disease and pattern of endometriosis, scientific evidence evaluating the impact and types of environmental factors on the occurrence of endometriosis is up to date poor and of low-quality [5,16-19].

\section{Conclusion}

More studies are needed to elucidate the role of genetic and environmental components on the pathogenesis of endometriosis among monozygotic twin not sharing the same environment.

\section{References}

1. Kennedy S, Bergqvist A, Chapron C, D'Hooghe T, Dunselman G, et al. (2005) ESHRE special interest group for endometriosis and endometrium guideline development group. ESHRE guideline for the diagnosis and treatment of endometriosis. Hum Reprod 20: 2698-2704.

2. Treloar SA, O'Connor DT, O'Connor VM, Martin NG (1999) Genetic influences on endometriosis in an Australian twin sample. Fertil Steril 71: 701-710.

3. Kennedy S, Mardon H, Barlow D (1995) Familial endometriosis. J Assist Reprod Genet 12: 32-34.

4. Matalliotakis IM, Arici A, Cakmak H, Goumenou AG, Koumantakis G, et al. (2008) Familial aggregation of endometriosis in the Yale Series. Arch Gynecol Obstet 278: 507-511.

5. Saha R, Pettersson HJ, Svedberg P, Olovsson M, Bergqvist A, et al. (2015) Heritability of endometriosis. Fertil Steril 104: 947-952.

6. Hadfield RM, Mardon HJ, Barlow DH, Kennedy SH (1997) Endometriosis in monozygotic twins. Fertil Steril 68: 941-942.

7. Lamb K, Hoffmann RG, Nichols TR (1986) Family trait analysis: A case-contro study of 43 women with endometriosis and their best friends. Am J Obstet Gynecol 154: 596-601

8. Moen MH, Magnus P (1993) The familial risk of endometriosis. Acta Obste Gynecol Scand 72: 560-564

9. Eisenberg VH, Weil C, Chodick G, Shalev V (2018) Epidemiology of endometriosis: A large population-based database study from a healthcare provider with 2 million members. BJOG An Int J Obstet Gynaecol 125: 55-62.

10. Nnoaham KE, Hummelshoj L, Webster P, D'Hooghe T, De Nardone CF, et al. (2011) World Endometriosis Research Foundation Global Study of Women's Health consortium. Impact of endometriosis on quality of life and work productivity: A multicenter study across ten countries. Fertil Steril 96: 366-373.

11. Abbas S, Ihle P, Köster I, Schubert I (2012) Prevalence and incidence of diagnosed endometriosis and risk of endometriosis in patients with endometriosis-related symptoms: Findings from a statutory health insurancebased cohort in Germany. Eur J Obstet Gynecol Reprod Biol 160: 79-83.

12. Hudelist G, Fritzer N, Thomas A, Niehues C, Pet O, et al. (2012) Diagnostic delay for endometriosis in Austria and Germany: Causes and possible consequences. Hum Reprod 27: 3412-3416.

13. Meuleman C, Vandenabeele B, Fieuws S, Spiessens C, Timmerman D, et al. (2009) High prevalence of endometriosis in infertile women with normal ovulation and normospermic partners. Fertil Steril 92: 68-74.

14. Somigliana E, Vigan P, Abbiati A, Gentilini D, Parazzini F, et al. (2010) Here comes the sun: Pigmentary traits and sun habits in women with endometriosis. Hum Reprod 25: 728-733.

15. Sulem P, Gudbjartsson DF, Stacey SN, Helgason A, Rafnar T, et al. (2007) Genetic determinants of hair, eye and skin pigmentation in Europeans. Nat Genet 39: 1443-1452.

16. Koninckx PP (1999) The physiopathology of endometriosis: Pollution and dioxin. In: Gynecol Obstet Invest 1: 47-50.

17. Parazzini F, Chiaffarino F, Surace M, Chatenoud L, Cipriani S, et al. (2004) Selected food intake and risk of endometriosis. Hum Reprod 19: 1755-1759.

18. Moen MH (1994) Endometriosis in monozygotic twins. Acta Obstet Gynecol Stand 73: 59-62.

19. Zondervan KT, Cardon LR, Kennedy SH, Martin NG, Treloar SA (2005) Multivariate genetic analysis of chronic pelvic pain and associated phenotypes. Behav Genet 35: 177-188. 